\title{
Oral Lichen Planus: Diagnosis and Management
}

\author{
Isaäc van der Waal \\ Department of Oral and Maxillofacial Surgery and Oral Pathology of the ACTA/VU University Medical Center, \\ Amsterdam, The Netherlands \\ Correspondence e-mail to: i.vanderwaal@vumc.nl
}

\begin{abstract}
Oral lichen planus (OLP) is a rather common oral disease, mainly affecting adults, occurring more often in women than in men. The etiopathogenesis is still unclear. The diagnosis may be cumbersome, even in the presence of a biopsy. In addition, there are several lesions that may resemble lichen planus (lichenoid lesions) both clinically and histopathologically. Treatment of OLP can only be symptomatic and usually consists of topical application of corticosteroids. The disease is characterized by remissions and exacerbations and may persist in some patients lifelong. There is an ongoing debate in the literature as whether OLP is a potentially malignant disease. Because of this uncertainty, annual follow-up is advised.
\end{abstract}

Key words: oral lichen planus; oral mucosa

\section{INTRODUCTION}

Lichen planus (LP) is a chronic mucocutaneous disorder which may involve the oral mucosa only ("isolated OLP") or in combination with involvement of other mucosal surfaces, e.g. vagina ("vulvovaginalgingival syndrome"), oesophagus, pharynx, and nails. It has been suggested that extra-oral involvement in oral lichen planus is more common than suspected. ${ }^{1,2}$ A few cases have been reported of transformation of OLP into mucous membrane pemphigoid, being referred to as lichen planus pemphigoides. ${ }^{3}$ Attention will be paid at the diagnostic aspects of OLP and lichenoid lesions, as well at the various treatment modalities. An important question whether OLP is a benign lesion or a potentially malignant one.

\section{Epidemiology}

The estimated prevalence of oral lichen planus is approximately $0.1 \%$, although figures varying from $1 \%$ to $4 \%$ have been reported in the literature. ${ }^{4}$ Oral lichen planus mainly affects middle-aged people and is more common among women than among men. ${ }^{5}$ Familial presentation is extremely rare. ${ }^{6}$ Oral lichen planus occurs mainly in non-smokers. ${ }^{7}$ Little is known about possible geographic differences.

\section{Etiology}

Lichen planus is most likely caused by T- cell autoimmunity. Apparently, Langerhans cells play an important role in this process. ${ }^{8}$ Controversial views have been reported about the role of human papilloma virus (HPV), particularly HPV 16. ${ }^{9,10}$ There is no evidence that psychological factors are a direct etiological factor. In some populations there is a significant, yet unexplained, association between lichen planus and hepatitis $\mathrm{C}$ virus. ${ }^{11}$ Yet, in other populations an association with thyroid diseases, especially hypothyroidism, has been reported. ${ }^{12}$

Lichen planus or lichen planus-like lesions, usually referred to as lichenoid lesions or lichenoid reactions, may occasionally be caused by certain drugs. ${ }^{13}$ Also prolonged, direct anatomic contact with large amalgam restorations ("contact lesion") may produce a lichenoid appearance of the oral mucosa. Furthermore, a chronic graft versus host reaction after an allogenic stem cell transplantation may strongly resemble OLP. Interestingly, the lower lip is a site of predilection in this particular patient population. 


\section{Clinical aspects Signs and symptoms}

Oral lichen planus has various clinical manifestations, such as reticular (characterized by white striae, also referred to as "Wickhams striae"), annular, papular, erythematous, plaque-type, ulcerative and bullous type. The reticular, the erythematous and the plaque types are the most common ones. The various types may occur simultaneously in an individual patient and may also change in time. (Figure. 1 and 2). It has been suggested that the plaque type is more common among smokers. There is nearly always a bilateral, more or less symmetrical distribution. The buccal mucosa, the gingiva and the dorsal surface of the tongue are the sites of predilection. Occurrence in the floor of the mouth and the palate is rare. Superficial mucoceles may develop within or adjacent to mucosal areas that are involved by lichen planus, while in dark-skinned people post-inflammatory melanosis has been reported to occur in the affected areas.

Particularly the erythematous type may cause symptoms, such as pain and, in case of gingival involvement, severe bleeding during toothbrushing. Patients affected by the erythematous or ulcerative type of OLP usually do not tolerate spicy food. When the gums are involved patients may complain about the esthetic aspect of their gums. In involvement of the gingiva the presence of the "vulvovaginal gingiva syndrome" should be considered.

The course of oral lichen planus is characterized by remissions and exacerbations with intervals of several weeks or months of both the clinical signs and the symptoms. There are various scoring systems, mainly designed for scientific studies, to quantify the clinical signs and symptoms of OLP. ${ }^{14}$

\section{Clinical differential diagnosis, including lichenoid lesions}

Llichenoid lesions may be caused by direct anatomic contact with a large (amalgam) restoration. Replacement of the restoration should result in healing of the lesion within several weeks, but this should be checked by the clinician. One may consider to take a biopsy before advising to have the amalgam restoration removed in order to exclude the possibility of a dysplastic or even a malignant lesion. The predictive value of epicutaneous patch testing for amalgam and mercury allergy is rather questionable. ${ }^{15,16}$ In contrast todrug-induced cutaneous lichenoid lesions drug-induced oral lichenoid lesions are extremely rare. Nevertheless, one may consider to adjust the medication (Box 1), if applicable. Of course, such adjustment requires communication with the prescribing specialist.

As has been mentioned already, lichenoid lesions may occur in chronic graft-versus-host disease, being clinically sometimes indistinguishable from "idiopathic" OLP. At
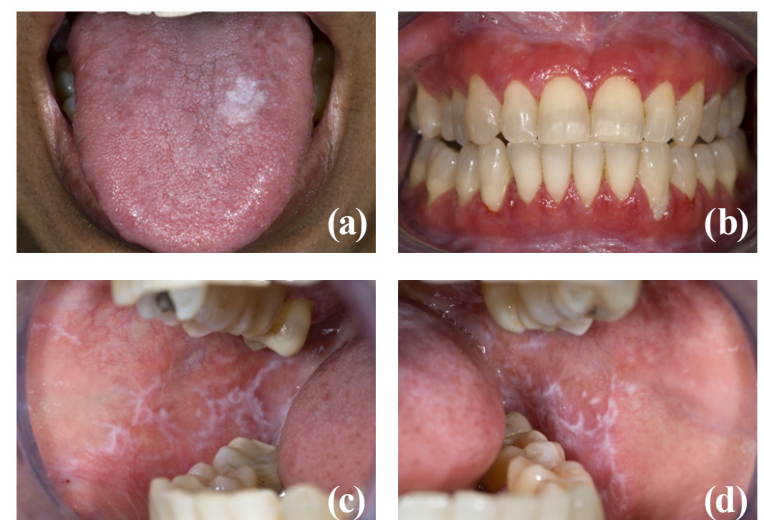

Figure 1. A 55-year-old woman with plaque-type OLP of the tongue (a), erythematous type of the gums (b) and reticular type on the buccal mucosa (c and d).
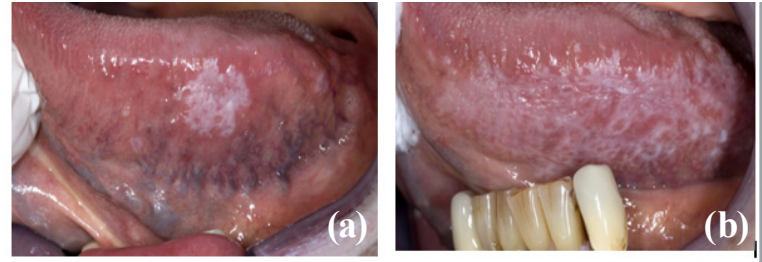

Figure 2. A 58-year-old woman with a somewhat plaque-type OLP at the lateral border of the tongue (a); after six weeks there is a distinct reticular pattern (b).

Box 1. Drugs possibly causing lichenoid lesions ${ }^{13}$

Antihypertensives (e.g. ACE inhibitors)
Oral hypoglycaemics (e.g. Tolbutamide)
Non-steroidal anti-inflammatory drugs
Second line anti-arthritics (gold; penicillamine)
Xanthine oxidase inhibitors (Allopurinol)
Psychoactive drugs (e.g. tricyclic antidepressants)
Diuretics (e.g. furosamide)
Antiparasitic drugs
Antimicrobial agents,including mouthrinses (e.g.
tetracycline)
Miscellaneous drugs (e.g. iodides, quinidine)

times, it may be difficult, if not impossible, to clinically distinguish oral lichen planus not only from lichenoid lesions but also from leukoplakia, lupus erythematodes, linear IgA disease, mucous membrane pemphigoid and some other white or red lesions of the oral mucosa. ${ }^{17}$ In some of these cases the medical history or other clinical features are helpful in establishing the correct diagnosis. Unfortunately, a biopsy is not always helpful in such cases. Some clinicians will always do a biopsy in case of oral lichen planus, while others take a biopsy only in case of doubt about the diagnosis.

\section{Histopathology}

In case of a distinct clinical diagnosis of lichen planus the histopathologic features are usually quite characteristic (Figure 3.). In scientific studies usually reference is made 


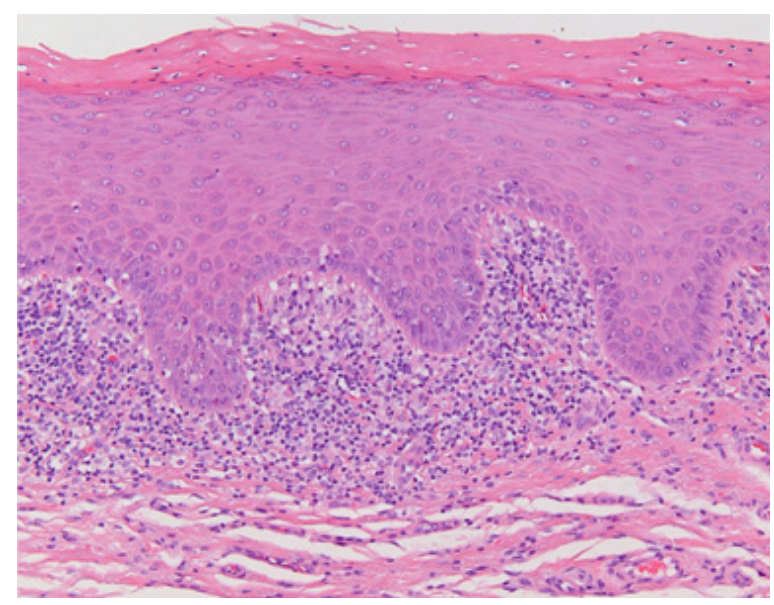

Figure 3. Low power view, rather suggestive of lichen planus (H-E; original magnification. X100)

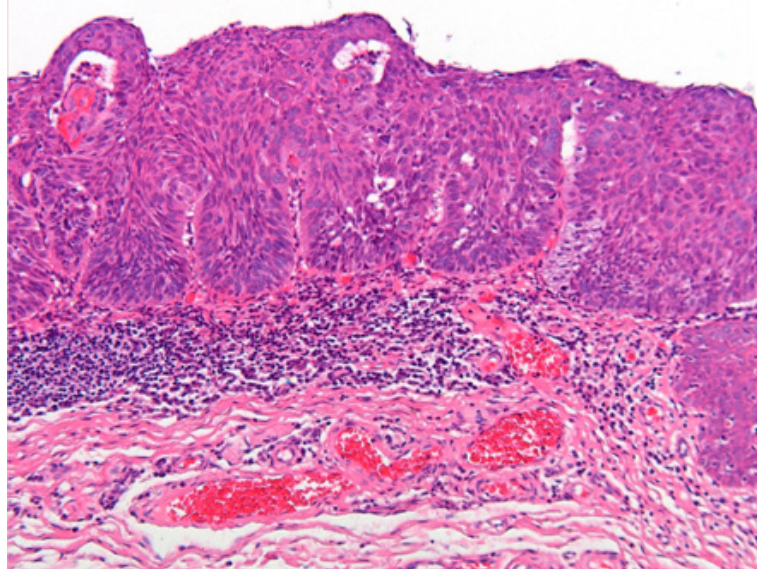

Figure 4. Severe epithelial dysplasia in a biopsy taken from a leukoplakia (H-E; original magnification X100). The bandlike subepithelial infiltrate is somewhat suggestive of OLP; hence the rather confusing term "lichenoid dysplasia"

to a definition study from the World Health Organization, published in $1978 .{ }^{18}$ However, these histologic criteria have not been validated. In another study it has been shown that there is no good correlation between the clinical diagnosis and the histopathologic diagnosis of OLP. ${ }^{19}$ It is, indeed, hardly justified to arrive at a firm diagnosis of OLP based on histopathologic examination only. Furthermore, there are opposing views of the possibility to histopathologically distinguish lichen planus from the various lichenoid lesions. ${ }^{20}$

Epithelial dysplasia is by most pathologists not accepted as compatible with a histopathologic diagnosis of lichen planus. Some pathologists use the term "lichenoid dysplasia" when reporting on leukoplakic lesions that show a subepithelial bandlike lymphocytic infiltrate in the presence of epithelial dysplasia (Figure 4.). The use of this term may erroneously be interpreted by the clinician as the presence of dysplastic changes in lichen planus. Lichen planus does not show characteristic features on immunofluorescent examination; nevertheless, such examination may be helpful to distinguish lichen planus from vesiculobullous diseases such as mucous membrane pemphigoid.
Is oral lichen planus potentially malignant and can such event be prevented?

Oral lichen planus is by some regarded as a premalignant condition, the annual malignant transformation rate being less than $1 \% .{ }^{21}$ If this event occurs, it usually concerns the tongue. ${ }^{6}$ The suggestion has been made that a certain cell surface marker on hematopoietic stem cells and early progenitor cells in the bone marrow, referred to as CD133, correlates with the progression to oral squamous cell carcinoma. ${ }^{22}$

Others have not found any evidence for a potentially malignant behavior. ${ }^{23}$ Anyhow, such malignant transformation can not be prevented, although it has been speculated that the use of topical steroids may prevent such event. ${ }^{24}$

\section{Treatment}

Oral lichen planus may last for many years, if not lifelong. ${ }^{25}$ There is no cure for oral lichen planus. Treatment can only be symptomatic and most commonly consists of topical or, occasionally systemic, corticosteroids. The use of corticosteroids may enhance the risk of the development of candidiasis, sometimes necessitating antimycotic therapy.

Also the use of many other drugs, e.g. tacrolimus, thalidomide, topical aloe vera, oral curcuminoids and lysopine has been reported. ${ }^{26}$ The efficacy of all these drugs is rather questionable. ${ }^{27}$ There are opposing views about the effect of removing all amalgam restorations, not just the ones directly related to a lesion. ${ }^{28,29}$ It has been shown that plaque control improves the symptoms of OLP with gingival involvement. ${ }^{30}$

A variety of other treatment modalities has been reported, such as surgical excision, laser evaporation, laser excision and photodynamic treatment. Such treatment modalities may be useful in persistent localized areas of lichenoid involvement.

\section{Follow-up}

Since the issue of premalignancy is still under debate, it seems safe practice to check the patient annually for any possible unfavorable change. However, it is questionable whether such follow-up is really effective in either preventing malignant transformation or in resulting in better survival in case of cancer development.

\section{REFERENCES}

1. Ebrahimi M, Lundqvist L, Wahlin YB, Nylander E. Mucosal lichen planus, a systemic disease requiring multidisciplinary care: a cross-sectional clinical review from a multidisciplinary perspective. J Low Genit Tract Dis. 2012;16:377-80.

2. Ramer MA, Altchek A, Deligdisch L, Phelps R, Montazem A, Buonocore PM. Lichen planus and the vulvovaginal-gingival syndrome. J Periodontol. 2003;74:1385-93.

3. Mignogna MD, Fortuna G, Leuci S, Stasio L, Mezza E, Ruoppo E. Lichen planus pemphigoides, a possible 
example of epitope spreading. Oral Surg Oral Med Oral Pathol Oral Radiol Endod. 2010;109:837-43.

4. McCartan BE,Healy CM. The reported prevalence of oral lichen planus: a review and critique. J Oral Pathol Med. 2008;37:447-53.

5. Gümrü B. A retrospective study of 370 patients with oral lichen planus in Turkey. Med Oral Patol Oral Cir Bucal. 2013;18:e427-32.

6. Bermejo-Fenoll A, Sanchez-Siles M, López-Jornet P, Camacho-Alonso F, Salazar-Sanchez N. Premalignant nature of oral lichen planus. A retrospective study of 550 oral lichen planus patients from south-eastern Spain. Oral Oncol. 2009;45:e54-6.

7. Budimir V, Richter I, Andabak-Rogulj A, VučićevićBoras V, Budimir J, Brailo V. Oral lichen planus - retrospective study of 563 Croatian patients. Med Oral Patol. 2014;19:e255-60.

8. Gueiros LA, Gondak R, Jorge Júnior J, Coletta RD, Carvalho Ade A, Leão JC, de Almeida OP, Vargas PA. Increased number of Langerhans cells in oral lichen planus and oral lichenoid lesions. Oral Surg Oral Med Oral Pathol Oral Radiol. 2012;113:661-6.

9. Payeras MR, Cherubini K, Figueiredo MA, Salum FG. Oral lichen planus: focus on etiopathogenesis. Arch Oral Biol. 2013;58:1057-69.

10. Montebugnoli L, Gissii DB, Scapoli L, Palmieri A, Morandi L, Manelli IM, Foschini MP. $\mathrm{P}^{16 \text { INK4 }}$ Expression is not associated with human papillomavirus in oral lichen planus. Oral Surg Oral Med Oral Pathol Radiol. 2014;118:694-702.

11. Carbone M, Arduino PG, Carrozzo M, Gandolfo S, Argiolas MR, Bertolusso G, Conrotto D, Pentenero M, Broccoletti R. Course of oral lichen planus: a retrospective study of 808 northern Italian patients. Oral Dis. 2009;15:235-43.

12. Siponen M, Huuskonen L, Läärä E, Salo T. Association of oral lichen planus with thyroid disease in a Finnish population: a retrospective case-control study. Oral Surg Oral Med Oral Pathol Oral Radiol Endod. 2010;110:319-24.

13. Rice PJ, Hamburger J. Drugs possibly causing lichenoid lesion. Dent Update. 2002; 29: 442-7.

14. Park HK, Hurwitz S, Woo SB. Oral lichen planus: REU scoring system correlates with pain. Oral Surg Oral Med Oral Pathol Oral Radiol. 2012;114:75-82.

15. Ostman PO, Anneroth G, Skoglund A. Amalgamassociated oral lichenoid reactions. Clinical and histologic changes after removal of amalgam fillings. Oral Surg Oral Med Oral Pathol Oral Radiol Endod. 1996;81:459-65.

16. Montebugnoli L, Venturi M, Gissi DB, Cervellati F. Clinical and histologic healing of lichenoid oral lesions following amalgam removal: a prospective study. Oral Surg Oral Med Oral Pathol Oral Radiol. 2012;113:766-72.

17. de Freitas Silva BS, Silva Sant'Ana SS, Watanabe S, Vêncio EF, Roriz VM, Yamamoto-Silva FP.
Multifocal red bands of the marginal gingiva. Oral Surg Oral Med Oral Pathol Oral Radiol. 2015;119:3-7.

18. WHO Collaborating Centre for Oral Precancerous Lesions. Definition of keukoplakia and related lesions: an aid to studies on oral precancer. Oral Surg Oral Med Oral Pathol. 1978;46:518-539.

19. van der Meij EH, van der Waal I. Lack of clinicopathologic correlation in the diagnosis of oral lichen planus based on the presently available diagnostic criteria and suggestions for modifications. J Oral Pathol Med. 2003;32:507-12.

20. Ismail SB, Kumar SK, Zain RB. Oral lichen planus and lichenoid reactions: etiopathogenesis, diagnosis, management and malignant transformation. J Oral Sci. 2007:49:89-106.

21. Bombeccari GP, Guzzi G, Tettamanti M, Giannì AB, Baj A, Pallotti F, Spadari F. Oral lichen planus and malignant transformation: a longitudinal cohort study. Oral Surg Oral Med Oral Pathol Oral Radiol Endod. 2011;112:328-34.

22. Sun L, Feng J, Ma L, Liu W, Zhou Z. CD133 expression in oral lichen planus correlated with the risk for progression to oral squamous cell carcinoma. Ann Diagn Pathol. 2013;17:486-9.

23. Eisenberg E. Oral lichen planus: a benign lesion. J Oral Maxillofac Surg. 2000;58:1278-85.

24. Otero-Rey EM, Suarez-Alen F, Peñamaria-Mallon M, Lopez-Lopez J, Blanco-Carrion A. Malignant transformation of oral lichen planus by a chronic inflammatory process. Use of topical corticosteroids to prevent this progression? Acta Odontol Scand. 2014;72:570-77.

25. Thorn JJ, Holmstrup P, Rindum J, Pindborg JJ. Course of various clinical forms of oral lichen planus. A prospective follow-up study of 611 patients. J Oral Pathol. 1988;17:213-8.

26. Thongprasom K, Prapinjumrune C, Carrozzo M. Novel therapies for oral lichen planus. J Oral Pathol Med. 2013;42:721-7.

27. Thongprasom K, Carrozo M, Furness S, Lodi $\mathrm{G}$. Interventions for treating oral lichen planus. Cochrane Database of Systemic Reviews 2011, Issue 7. Art. No.CD001168.

28. Dunsche A, Kästel I, Terheyden H, Springer IN, Christophers E, Brasch J. Oral lichenoid reactions associated with amalgam: improvement after amalgam removal. Br J Dermatol. 2003;148:70-6.

29. Mårell L, Tillberg A, Widman L, Bergdahl J, Berglund A. Regression of oral lichenoid lesions after replacement of dental restorations. J Oral Rehabil. 2014;41:381-91.

30. Salgado DS, Jeremias F, Capela MV, Onofre MA, Massucato EM, Orrico SR. Plaque control improves the painful symptoms of oral lichen planus gingival lesions. A short-term study. J Oral Pathol Med. 2013;42:728-32.

(Received September 30, 2015; Accepted November $6,2015)$ 